ORIGINAL ARTICLE

\title{
Return to the origin: what creates a procrastination identity?
}

\author{
Thomas P. Tibbett ${ }^{1 \cdot A, C, D, E}$, foseph R. Ferrari ${ }^{2 \cdot A, B, F}$ \\ 1: Texas A\&M University, College Station, Texas, United States \\ 2: DePaul University, Chicago, Illinois, United States
}

BACKGROUND

Procrastination affects over $20 \%$ of adult men and women, with current international data indicating a global preference to systematically delay the start or completion of intended tasks. Procrastination is a common, sub-optimal decision-making strategy that emphasises short-term benefits at the expense of later performance. Some individuals develop a pattern of procrastination which proves difficult to break; worse, they may begin to identify as a procrastinator, setting themselves up for failure.

\section{PARTICIPANTS AND PROCEDURE}

The current investigation examined what develops a procrastinator identity. Previous research indicated that chronic procrastination is a learned tendency beginning in one's early development from parental control approaches. We extended that line of research using a cross-cultural sample $(n=2124)$, self-reported procrastination (behavioural or decisional), and retrospective regret scores in 12 domains. We used logistic regression to predict the likelihood of explicitly identifying as a procrastinator.
RESULTS

Across three randomised partitions, results indicated that indecision and regrets about education, career, and finances most increased the likelihood of identifying as a procrastinator.

\section{CONCLUSIONS}

These findings support that regrets largely influenced by earning-potential best predict procrastination identity. The current results are consistent with other studies assessing the causes and consequences of chronic procrastination regardless of country or ethnic background. Future research is needed.

\section{KEY WORDS}

identity; procrastination; regret; indecision; machine learning

CORResponding Author - Prof. Joseph R. Ferrari, DePaul University, 2219 North Kenmore Ave, 60614 Chicago, Illinois,

United States, e-mail: jferrari@depaul.edu

Authors' COntributions - A: Study design - B: Data collection · C: Statistical analysis · D: Data interpretation .

E: Manuscript preparation · F: Literature search

TO CITE THIS ARTICLE - Tibbett, T. P., \& Ferrari, J. R. (2019). Return to the origin: what creates a procrastination identity?

Current Issues in Personality Psychology, 7(1), 1-7.

RECEIVED 10.07.2017 · REVIEWED 15.10.2017 · ACCEPTED 12.02.2018 · PUBLISHED 21.05.2018 


\section{BACKGROUND}

Psychological science has often illustrated that "if men define situations as real, they are real in their consequences" (Thomas \& Thomas, 1928, p. 529). Recent work on affect (e.g. Schwarz, 2012), the placebo effect (Tuttle et al., 2015), and decision-making (Byrne, Tibbett, Laserna, Carter-Sowell, \& Worthy, 2015) has demonstrated that human behaviour is often moderated by self-perception. Belief, here, creates reality: one's perception shapes who they are and how they behave. However, these beliefs are not always true; they may simply hurt their performance, such as in the self-fulfilling prophecy - a prediction that causes itself to become true due to positive feedback between belief and behaviour (e.g. Bandura, 1977; Merton, 1948). These expectancy effects negatively impact physical (e.g. Eden \& Zuk, 1995), educational (e.g. Agirdag, Van Avermaet, \& Van Houtte, 2013), developmental (e.g. Pikhartova, Bowling, \& Victor, 2016; Wurm, Warner, Ziegelmann, Wolff, \& Schüz, 2013), and health (e.g. Moston, Engelberg, \& Skinner, 2015) outcomes. Individuals prone to the self-fulfilling prophecy may identify as incapable (for example, "I am not a good test-taker"), thereby preventing themselves from being capable unless they change their frame of mind.

One common example where individuals label themselves this way is when procrastinating, defined as purposefully delaying the start or completion of tasks for irrational reasons (Ferrari, 2010; Ferrari, Johnson, \& McCown, 1995). Everyone in some measure procrastinates, but for an estimated $20 \%$ of U.S. citizens, these frequent delays become a significant problem (Harriott \& Ferrari, 1996). It is easy to see that chronic procrastination may lead to regrets. The literature suggests that chronic procrastination causes negative impacts in academic (Klassen, Krawchuk, \& Rajani, 2008), health (Pychyl \& Sirois, 2016), and social (Ferrari \& Patel, 2004; Klingsieck, 2013) domains. Putting things off appears to lead to regret. Research suggests that chronic procrastinators especially regret their experiences regarding education, parenting, family, friends, health, and finances (Ferrari, Barnes, \& Steel, 2009; Ferrari \& Tibbett, 2017). In fact, the most common regret in the U.S. may be inaction and indecision; metaanalyses indicated that people wished that they had taken their responsibilities more seriously (Gilovich \& Medvec, 1995; Roese \& Summerville, 2005).

Yet, for all the problems of putting off, it appears to be socially acceptable in the U.S. to procrastinate (e.g. Tibbett \& Ferrari, 2018) and fall into self-fulfilling prophecies ("I consider myself a procrastinator"), which hinder performance. Although much research has focused on coping with procrastination and its correlates, very little work has involved the factors that create and perpetuate procrastination identity: the specific admission that procrastination is a part of who they are. If we, as researchers, can indicate the most impactful regrets for developing this identity, we may be able to prevent people from identifying as procrastinators and perpetuating the problem. The current investigation explored what forms of procrastination and regret increased the likelihood of identifying as a procrastinator. We first measured the difference in procrastination scores between those who identified as a procrastinator and those whom did not. We hypothesised that individuals expressing that they were a procrastinator would have higher procrastination scores.

Next, we utilised commonly accepted measures of procrastination (behavioural, decisional) and a well-known metric of various regret domains to predict procrastination identity. As researchers, we were interested in narrowing down which factors most increased the odds of labelling oneself. Being able to understand which types of procrastination and regret domains increase risk for procrastination identity could allow clinicians to identify high-risk individuals. This information may allow tailoring of interventions relevant to them, a more proactive role than current work in procrastination.

\section{PARTICIPANTS AND PROCEDURE}

\section{PARTICIPANTS}

A national dataset was collected via snowball sampling, using an online forum to collect data anonymously $(N=2893)$. In terms of age, the typical participant was in their thirties $(M=36.60, M d n=32.50$, $S D=13.12$ ). Participants were generally middleclass, judging by income converted to U.S. dollars $(M=57,050, M d n=45,000, S D=55,446.83)$. However, there were several outlier participants who made up to $\$ 250,000$ annually.

\section{MEASURES}

Participants completed a single-item, binary procrastination identity question ("would you consider yourself a procrastinator?"), two procrastination inventories, and one regret inventory. The order of display was randomised to prevent order effects. For procrastination, we included a measure of behavioural procrastination: the Adult Inventory of Procrastination (AIP: McCown, Johnson, \& Petzel, 1989). This seven-point scale (1 - completely false, 7 - completely true) included examples such as "I am not very good at meeting deadlines". Higher scores indicated higher frequency of behavioural procrastination in daily life. The typical participant engaged in some 
Table 1

Mean score on procrastination and regret indices

\begin{tabular}{|c|c|c|c|}
\hline & M & $S D$ & Description \\
\hline & & & Procrastination scales: \\
\hline AIP scale & 4.18 & 0.32 & Behavioural procrastination \\
\hline \multirow[t]{2}{*}{ DP scale } & 3.09 & 0.97 & Decisional procrastination: indecision \\
\hline & & & Regret categories: \\
\hline Career & 3.21 & 1.32 & Jobs, employment, earning a living \\
\hline Community & 3.21 & 1.32 & Volunteer work, political activism \\
\hline Education & 3.20 & 1.43 & School, studying, getting good grades \\
\hline Family & 2.69 & 1.29 & Interactions with parents and siblings \\
\hline Finance & 2.94 & 1.39 & Decisions about money \\
\hline Friends & 2.91 & 1.28 & Interactions with close others \\
\hline Health & 3.43 & 1.32 & Exercise, diet, avoiding or treating illness \\
\hline Leisure & 2.60 & 1.29 & Sports, recreation, hobbies \\
\hline Parenting & 2.24 & 1.22 & Interactions with offspring \\
\hline Romance & 3.00 & 1.43 & Love, sex, dating, marriage \\
\hline Spirituality & 2.46 & 1.37 & Religion, philosophy, the meaning of life \\
\hline Self & 2.84 & 1.34 & Improving oneself in terms of abilities, attitudes, behaviours \\
\hline
\end{tabular}

procrastination behaviours $(M=4.18, S D=0.32)$. For our study, the AIP items were internally consistent $(\alpha=.89)$.

We also included a measure of indecision: the Decisional Procrastination subscale of the Melbourne Decision Making Questionnaire (DP: Mann, Burnett, Radford, \& Ford, 1997). Decisional procrastination scores include appraisals of decision-making along a fivepoint rating scale (1 - strongly disagree, 5 - strongly agree) with items such as "I feel uncomfortable about making decisions”. Higher scores reflected an increasing motivational deficit, in which participants put off making a decision when faced with multiple choices. The typical participant was moderately indecisive $(M=3.09, S D=0.97)$. The responses on this scale, like AIP, were internally consistent $(\alpha=.90)$.

For regret, we used the 12-item Life Domain Regret Inventory pioneered by Roese and Summerville (2005). This scale consists of prompts in which participants reflect on how much they regret past decisions in each life domain on a five-point response scale $(1-$ a little regret, 5 - a lot of regret). The 12 domains included career, community, education, family, finance, friends, health, leisure, parenting, romance, spirituality, and self-oriented regrets. Higher scores indicated greater regret in those domains. Each domain was described in the item to prevent participant confusion. An example item was "Education: school, studying, getting good grades". All 12 domains were considered single-item factors. A full listing of descriptive statistics and examples is included in Table 1.

After these scales, participants reported demographic information. This included age, gender, and income. Other items were included that were unrelated to the intent of the study.

\section{DATA PARTITIONING}

A binary classification model was proposed to fit the global dataset (i.e. logistic regression). In total, 2124 participants completed all measures and were entered for analysis, with six participants not completing all regret items. Using data science best practices, the dataset was randomly partitioned proportionally into a training set $(40 \%, n=823)$, validation set $(40 \%$, $n=869)$, and test set $(20 \%, n=432)$. In machine learning, a training set is often used to screen non-significant variables: fitting the model. The purpose of the validation set is to replicate the training set and debunk potential overfitting: validating the model. Finally, when the first two partitions are appropriately similar, the test set is used for parameter estimates and classification on a smaller subset (the test set) to minimise Type I error: applying the model. 
Table 2

Training, validation, and test set summary

\begin{tabular}{lccccc}
\hline Set & $n$ & $R^{2}$ & AUC & Correct & Improvement \\
\hline Training & 823 & .40 & .89 & $89 \%$ & $78 \%$ \\
Validation & 869 & .40 & .88 & $88 \%$ & $76 \%$ \\
Test & 432 & .43 & .89 & $90 \%$ & $80 \%$ \\
\hline
\end{tabular}

Note. $N=2,124$. Three partitions were randomly created in a 40/40/20 split. All three partitions were similar, demonstrating good fit $\left(R^{2}\right)$, high area-under-the-curve (AUC), and correct rate of classification (Correct). These partitions substantially outperformed random chance models (Improvement).

\section{RESULTS}

\section{DESCRIPTIVE STATISTICS}

In the eligible sample, 1851 of the 2124 participants considered themselves a procrastinator with the single-item identity question. Table 1 presents summarised descriptive statistics, as well as example responses to regret items given to participants. As noted from the table, the typical participant engaged in daily procrastination behaviours on the AIP. Indecision (DP) scores reflected that overall participants were also somewhat indecisive. Distributions appeared normal in distribution with few outliers. In short, the overall sample typically anchored on moderate scores for both procrastination measures. Regret scores were calculated independently, rather than averaged into a singular value, consistent with Roese and Summerville (2005). Overall, participants reported moderate regret on all 12 items, typically clustered around the median value of the five-point scale.

To verify validity of our binary procrastination identity item, an independent sample $t$-test was used to assess a difference in procrastination scores between those who considered themselves a procrastinator and those whom did not. For AIP, results indicated that participants who self-identified as procrastinators engaged in more procrastination behavior $(M=4.20, S D=0.31)$ than those whom did not consider themselves a procrastinator $(M=4.04$, $S D=0.29), t(2,122)=7.96, p<.001$. This difference was small to moderate in effect size $(d=.35)$. For $\mathrm{DP}$, results indicated that participants with a procrastinator identity were more indecisive $(M=3.16$, $S D=0.92)$ than those whom did not consider themselves a procrastinator $(M=2.06, S D=0.72)$, $t(2,122)=19.11, p<.001$. The practical significance of this group difference was large $(d=.83)$. In short, these results indicated that identifying as a procrastinator might suggest greater procrastination tendencies and behaviour.

\section{TRAINING AND VALIDATION SETS}

Initially, an exploratory stepwise regression identified indecision, gender, and five types of regret (of the original 12) as predictors of whether individuals felt they were a procrastinator (Yes/No). However, a review of the training model indicated that some of these predictors were not significant at the sufficient level of risk for psychological science $(p<.05)$. Therefore, non-significant variables were removed from the training model, one at a time, until all remaining factors were significant. In the final training set, significant variables were indecision, education regret, career regret, and financial regret. These were the best predictors of self-identifying as a procrastinator.

Using these four variables as predictors, a binary classification model was fitted to the training and validation partitions. The results (summarised in Table 2) indicated very similar fit indices. Generalised $R$-squared, a measure of variance explained, was nearly identical for the training set $\left(R^{2}=.40\right)$ and validation set $\left(R^{2}=.40\right)$. For both these partitions, believing in oneself as a procrastinator was often correctly identified in the training set $(88 \%)$ and the validation set $(87 \%)$, respectively; for reference, truly random classification would result in $50 \%$ correct. Receiver operating character (ROC) curves were created for comparison (e.g. Swets, 1986). The area-under-thecurve (AUC) in both training (.88) and validation (.87) sets met signal detection theory standards (e.g. Stanislaw \& Todorov, 1999). Overall, judging by the reliable fit indices, an appropriate model fit was identified in the training set and cross-validated by the validation set. These results suggest the model did not overfit the data. This four-variable model was applied to the test data set.

\section{TEST SET}

According to parameter estimates, education regret $\left(\chi_{(1)}^{2}=40.40, p<.001\right)$, indecision $\left(\chi_{(1)}^{2}=15.48\right.$, $p<.001)$, financial regret $\left(\chi_{(1)}^{2}=13.35, p<.001\right)$, and career regret $\left(\chi_{(1)}^{2}=13.34, p<.001\right)$ were all in- 
tegral to a significant overall classification model, $\chi_{(4)}^{2}=190.50, p<.001$. Higher scores on each of the four variables, respectively, predicted greater likelihood of believing oneself a procrastinator. Consulting confidence intervals, we found that none of these parameters were significantly different from each other; all intervals overlapped.

Fit indices for the test set were consistent with the previous partitions. The model explained a considerable amount of variance $\left(R^{2}=.43\right)$ and often classified participants correctly $(90 \%)$. The model far outperformed classifying by random chance (50\%), resulting in about an $80 \%$ improvement in performance (from $50 \%$ to $90 \%$ ). Figure 1 contains an ROC curve visualising this improvement; the AUC (.89) met high standards (Stanislaw \& Todorov, 1999). A confusion matrix was generated to understand when the model misclassified participants (see Table 3). Overall, the model often correctly identified self-reported procrastinators (sensitivity: .86) but had more difficulty correctly identifying non-procrastinators (specificity: .70). It was more likely for a non-procrastinator to be falsely classified as a procrastinator than viceversa; as such, the model was liberal.

\section{DISCUSSION}

The current investigation concerned what forms of procrastination and regret associated with procrastinating identity. Overall, the results indicated robust findings across partitions of the dataset, replicating the results three times. In all three cases, higher scores in indecision and three specific forms of regret (education, financial, and career) increased the likelihood of procrastination identity. Behavioural procrastination and the other nine forms of regret were either non-significant or overshadowed by the other predictors.

These findings have a significant impact on the procrastination literature. Our sample from the USA scored moderately on both forms of procrastination; however, dividing into the indicated groups, there were substantial differences in procrastination between those who identified as a procrastinator and those who did not. Those persons with a procrastinator identity often engaged in more procrastination behaviours and almost certainly more indecision. Considering procrastination identity may be important for treatment and prevention - it appears to pair with more frequent, suboptimal decision-making. Interestingly, procrastinator identity participants still had moderate scores, suggesting that procrastination identity does not need high levels of procrastination to develop.

Our models indicated that indecision (as opposed to procrastination behaviour) increased one's likelihood of identifying as a procrastinator. This result

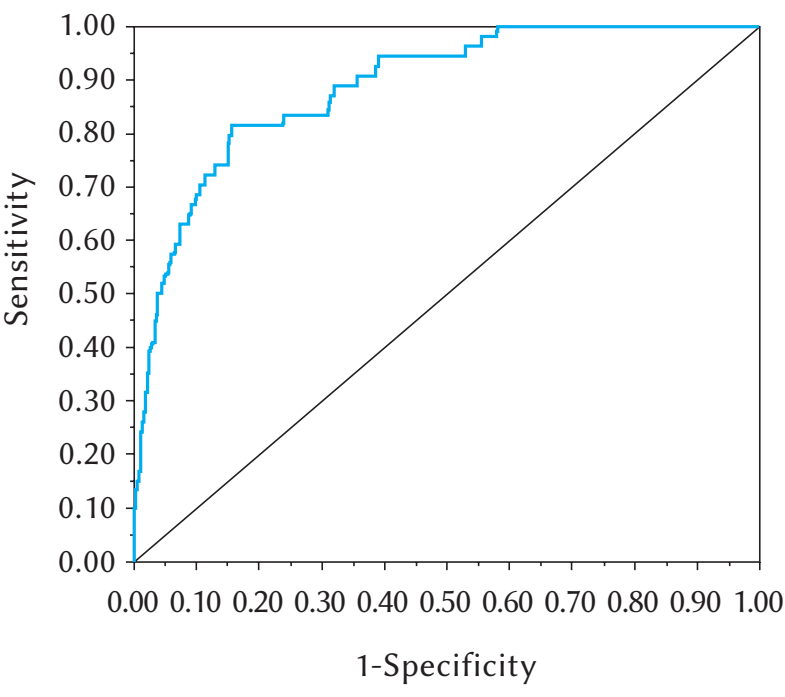

Figure 1. ROC curve. The test model (upper line) outperformed random chance (diagonal) with a high area under the curve value (.89). Using this model was about $80 \%$ better than chance at correctly classifying an individual with a procrastinator identity.

Table 3

Confusion matrix

\begin{tabular}{ccc}
\hline & \multicolumn{2}{c}{ Predicted } \\
\hline & Yes & No \\
Actual & & \\
Yes & 369 & 9 \\
No & 36 & 18 \\
\hline
\end{tabular}

Note. $N=2,124$. The test partition model's predicted responses based on procrastination and regret factors compared with actual responses. Correct categorisations are on the upper-left and lower-right diagonal.

builds on previous studies examining the differences between decisional and behavioural procrastination. Prior work has indicated that indecision and behavioural procrastination are highly correlated but can be distinguished by personality correlates and outcomes (e.g. Tibbett \& Ferrari, 2015; Ferrari \& Tibbett, 2017). To be clear, our model does not indicate that behavioural procrastination has zero impact on the odds of procrastinator identification. The contributions are relative to each other. As such, the model illustrates that, of the two forms of procrastination, indecision is most impactful, enough to render behavioural procrastination's contribution trivial.

The current investigation also adds to the regret literature: specifically, we found what types of regret might change self-perception and identity. In our study, regrets about career, education, and finances were the most impactful, increasing the odds of procrastinator identification. Though this is an initial study, all three regrets may surround a monetary 
component. It is possible that an individual may regret their career opportunities and choices for compensation, perhaps wishing they could start over and do something more rewarding. For education, typically the most common regret in the United States (Roese \& Summerville, 2005), a person might regret how lackadaisically they acted in school, preventing career advancement. Finally, financial regrets are often monetary, concerning spending or investments that may have been rewarding in the short-term but costly in the long-term. These regrets appear to influence earning potential later in life. Our study suggests that these specific regrets, ones that appear to have ramifications on resources, increase the probability of identifying as a procrastinator most. In contrast, social regrets such as friends, family, and relationships) did not register as primary factors.

There were some limitations to our study design, however. Data collection used snowball-sampling, resulting in a non-random sample. This fact also may explain why the majority identified as procrastinators. Prior research indicated that about $20 \%$ of individuals are chronic procrastinators in the United States (Ferrari, 2010; Ferrari \& Tibbett, 2017); most people, it would seem, would not identify as a procrastinator, but this was not reflected in our sample. One explanation could be that individuals were not asked in a clinical context; perhaps a procrastinator does not equate to a chronic procrastinator. Logistic regression models in classification and area-underthe-curve analyses are robust to unequal groups, but it is possible that the effects could be masked by simply having too many procrastinators. Finally, we did not collect qualitative data to suggest what individuals regretted most. We decided not to pursue episodic regrets for practical reasons - explaining specific regrets would significantly lengthen the study and influence regret scores in other domains. Emotion and counterfactual research would suggest that a state of regret would carry over to other domains (e.g. Lench, Bench, Darbor, \& Moore, 2015; Lench, Tibbett, \& Bench, 2016; Kwong, Wong, \& Tang, 2013; Smallman, 2013), artificially inflating scores. Future research should specifically characterise the memories remembered by those explicitly identifying as procrastinators.

Taken together, these findings suggest that indecision (being unable to make a decision) and resource-oriented regret best predict identifying as a procrastinator. These results may inform future interventions for identifying those at risk and suggest modes of treatment before they self-identify as procrastinator. We hope that these remaining questions of episodic regret will be addressed in future studies and not be postponed.

\section{References}

Agirdag, O., Van Avermaet, P., \& Van Houtte, M. (2013). School segregation and math achievement: A mixed-method study on the role of selffulfilling prophecies. Teachers College Record, 115, $1-50$.

Bandura, A. (1977). Self-efficacy: Toward a unifying theory of behavioral change. Psychological Review, 84, 191-215.

Byrne, K. A., Tibbett, T. P., Laserna, L. N., CarterSowell, A. C., \& Worthy, D. A. (2015). Ostracism reduces reliance on poor advice from others during decision making. Journal of Behavioral Decision Making, 29, 409-418.

Eden, D., \& Zuk, Y. (1995). Seasickness as a selffulfilling prophecy: raising self-efficacy to boost performance at sea. Journal of Applied Psychology, 80, 628-635.

Ferrari, J. R. (2010). Still procrastinating? The no regrets guide to getting it done. New York: J. Wiley \& Sons.

Ferrari, J. R., Barnes, K. L., \& Steel, P. (2009). Life regrets by avoidant and arousal procrastinators: Why put off today what you will regret tomorrow? Journal of Individual Differences, 30, 163-168.

Ferrari, J. R., Johnson, J. L., \& McCown, W. G. (1995). Procrastination and task avoidance: Theory, research, and treatment. New York, NY: Plenum Press.

Ferrari, J. R., \& Patel, T. (2004). Social comparisons by procrastinators: Rating peers with similar or dissimilar delay tendencies. Personality and Individual Differences, 37, 1493-1501.

Ferrari, J. R., \& Tibbett, T. P. (2017). Procrastination. In V. Zeigler-Hill \& T. K. Shackelford (eds.), Encyclopedia of Personality and Individual Differences (pp. 1-8). New York: Springer Meteor Press.

Gilovich, T., \& Medvec, V. H. (1995). The experience of regret: what, when, and why. Psychological Review, 102, 379-395.

Harriott, J., \& Ferrari, J. R. (1996). Prevalence of procrastination among samples of adults. Psychological Reports, 78, 611-616.

Klassen, R. M., Krawchuk, L. L., \& Rajani, S. (2008). Academic procrastination of undergraduates: Low self-efficacy to self-regulate predicts higher levels of procrastination. Contemporary Educational Psychology, 33, 915-931.

Klingsieck, K. B. (2013). Procrastination: When good things don't come to those who wait. European Psychologist, 18, 24-34.

Kwong, J. Y., Wong, K. F. E., \& Tang, S. K. (2013). Comparing predicted and actual affective responses to process versus outcome: An emotion-as-feedback perspective. Cognition, 129, 42-50.

Lench, H. C., Bench, S. W., Darbor, K. E., \& Moore, M. (2015). A functionalist manifesto: goal-related emotions from an evolutionary perspective. Emotion Review, 7, 90-98. 
Lench, H. C., Tibbett, T. P., \& Bench, S. W. (2016). Exploring the toolkit of emotion: What do sadness and anger do for us? Social and Personality Psychology Compass, 10, 11-25.

Mann, L., Burnett, P., Radford, M., \& Ford, S. (1997). The Melbourne Decision Making Questionnaire: An instrument for measuring patterns for coping with decisional conflict. Journal of Behavioral Decision Making, 10, 1-19.

McCown, W., Johnson, J., \& Petzel, T. (1989). Procrastination, a principal components analysis. Personality and Individual Differences, 10, 197-202.

Merton, R. K. (1948). The self-fulfilling prophecy. The Antioch Review, 8, 193-210.

Moston, S., Engelberg, T., \& Skinner, J. (2015). Selffulfilling prophecy and the future of doping. Psychology of Sport and Exercise, 16, 201-207.

Pikhartova, J., Bowling, A., \& Victor, C. (2016). Is loneliness in later life a self-fulfilling prophecy? Aging and Mental Health, 20, 543-549.

Pychyl, T. A., \& Sirois, F. M. (2016). Procrastination, emotion regulation \& well-being. In F. M. Sirois \& T. A. Pychyl (eds.), Procrastination, health and well-being (pp. 163-188). New York, NY: Elsevier.

Roese, N.J., \& Summerville, A. (2005). What we regret most... and why. Personality and Social Psychology Bulletin, 31, 1273-1285.

Schwarz, N. (2012). Feelings-as-information theory. In Van Lange P. A. M., Kruglanski A. W., Higgins E. T. (eds.), Handbook of theories in social psychology (pp. 289-308). Thousand Oaks, CA: SAGE.

Smallman, R. (2013). It's what's inside that counts: The role of counterfactual content in intention formation. Journal of Experimental Social Psychology, 49, 842-851.

Stanislaw, H., \& Todorov, N. (1999). Calculation of signal detection theory measures. Behavior Research Methods, Instruments, \& Computers, 31, 137-149.

Swets, J. A. (1986). Form of empirical ROCs in discrimination and diagnostic tasks: Implications for theory and measurement of performance. Psychological Bulletin, 99, 181-198.

Thomas, W. I., \& Thomas, D. (1928). The child in America. New York: Knopf.

Tibbett, T. P., \& Ferrari, J. R. (2015). The portrait of a procrastinator: Risk factors and results of indecision. Personality and Individual Differences, 82, 175-184.

Tibbett, T. P., \& Ferrari, J. R. (2018). The U.S. as a procrastiNATION: Assessing indecision on life satisfaction and life regret. North American Journal of Psychology, 19 (in press).

Tuttle, A. H., Tohyama, S., Ramsay, T., Kimmelman, J., Schweinhardt, P., Bennett, G. J., \& Mogil, J. S. (2015). Increasing placebo responses over time in US clinical trials of neuropathic pain. Pain, 156, 2616-2626.
Wurm, S., Warner, L. M., Ziegelmann, J. P., Wolff, J. K., \& Schüz, B. (2013). How do negative self-perceptions of aging become a self-fulfilling prophecy? Psychology and Aging, 28, 1088-1097. 